\title{
Yield and Seed Quality of Soybean Cultivars Infected with Sclerotinia sclerotiorum
}

D. D. Hoffman, Department of Crop Sciences; G. L. Hartman, USDA Agricultural Research Service and Department of Crop Sciences; and D. S. Mueller, R. A. Leitz, C. D. Nickell, and W. L. Pedersen, Department of Crop Sciences, University of Illinois at Urbana-Champaign, Urbana 61801-4723

\begin{abstract}
Hoffman, D. D., Hartman, G. L., Mueller, D. S., Leitz, R. A., Nickell, C. D., and Pedersen, W. L. 1998. Yield and seed quality of soybean cultivars infected with Sclerotinia sclerotiorum. Plant Dis. 82:826-829.

Sclerotinia stem rot (SSR) is one of the most important diseases of soybean in the United States. Five maturity group III cultivars, Asgrow A3304 STS (A3304), Pioneer Brand 9342 (P9342), Pioneer Brand 9381 (P9381), Probst, and Yale, grown in fields in east-central Illinois, were used to determine the relationship of SSR incidence to yield, 100-seed weight, seed protein and oil content, visual seed quality, and seed germination. In addition, the number of sclerotia in seed samples and the seedborne incidence of Sclerotinia sclerotiorum were determined. For each cultivar, at least 23 two-row plots, $3 \mathrm{~m}$ long, that represented a range of SSR incidence from low to high, were used to count the number of plants with and without SSR stem symptoms and were used to estimate yields and evaluate seed quality. Disease incidence ranged from 2 to $45 \%$ for Probst, 0 to 65\% for P9381, 0 to 68\% for P9342, 1 to 93\% for Yale, and 0 to 95\% for A3304. Regression of yields on SSR incidences for each cultivar was significant $(P<0.05)$; for every $10 \%$ increase in SSR incidence, yields were reduced by $147,194,203,254$, and $263 \mathrm{~kg} / \mathrm{ha}$ for Probst, A3304, P9342, Yale, and P9381, respectively. Disease incidence was negatively correlated $(P<0.05)$ with seed germination for all cultivars but Probst, and to oil content and seed weight for P9381 and Yale. Disease incidence was positively correlated $(P<0.05)$ with seed quality for all cultivars and to the number of sclerotia in harvested seeds for P9342, P9381, and Probst. The seedborne incidence of $S$. sclerotiorum was $0.3,0.3,0.3,0.4$ and $0.7 \%$ in A3304, P9381, Yale, Probst, and P9342, respectively, and represents a significant potential for further spread of this pathogen and disease.
\end{abstract}

Additional keywords: epidemic, seed quality, white mold, yield loss

Sclerotinia stem rot (SSR) of soybean (Glycine max (L.) Merr.), caused by Sclerotinia sclerotiorum (Lib.) de Bary, has become a major disease of soybean. In 1994, SSR was ranked as the second most important soybean disease in the United States and the most important disease in Argentina (25). Substantial yield losses caused by SSR have been reported in Michigan (7), North Dakota (17), Wisconsin (13), and Ontario, Canada (5). Sclerotinia stem rot was first reported in Illinois in 1946 by Chamberlain (6) and has

Corresponding author: G. L. Hartman

E-mail: ghartman@uiuc.edu

Trade and manufacturer's names are necessary to report factually on available data; however, the USDA neither guarantees nor warrants the standard of the product, and the use of the name by the USDA implies no approval of the product to the exclusion of others that may also be suitable.

Accepted for Publication 25 March 1998.

Publication no. D-1998-0428-01S

(C) 1998 The American Phytopathological Society observed at the canopy level include wilting and necrosis of leaves, which often remain attached to the main stem after plant death $(8,12,14,22)$. Initial signs of $S$. sclerotiorum are white, fluffy mycelia on infected plant tissue, and black sclerotia found externally and internally on the main stem, lateral branches, pods, and seed $(6,12,14)$. Environmental conditions that enhance SSR development include extended plant surface wetness $(5,7,8,10,13)$, cool and moist soil (10), and cool canopy temperatures caused by canopy closure $(5,7,10,16)$. Soilborne sclerotia form apothecia, which release ascospores that germinate to colonize senescing flower parts. The mycelia subsequently colonize leaf axils and nodes, then advance bilaterally on the main stems and lateral branches $(5,8,14)$.

The reactions of soybean cultivars to $S$. sclerotiorum have been described based on field $(4,7,12,14,17)$, growth room (3), and greenhouse $(7,8,12,15,16)$ evaluations. Disease incidence $(4,7)$ and severity indices $(12,16,17)$ have been used to evaluate the reaction of soybean cultivars to SSR in the field. Mechanisms of resistance to $S$. sclerotiorum in soybean germplasm are not known, but factors such as plant architecture, relative maturity, and lodging characteristics may influence disease incidence and severity (11). Resistance and/or tolerance to $S$. sclerotiorum has been reported in Phaseolus coccineus (1) and P. vulgaris $(2,9)$.

Other than the initial report of SSR in Illinois (6) and a disease survey (15), there since been reported in various locations in the northern areas of the state. In 1996, an SSR epidemic was found as far south as Iroquois County in east-central Illinois (15).

Symptoms of SSR first appear as watersoaking of the flowers $(8,14)$. Lesions develop on the petioles, main stem, and lateral branches $(5,8,12,14,16)$ and often result in pod abortion $(5,14)$. Symptoms

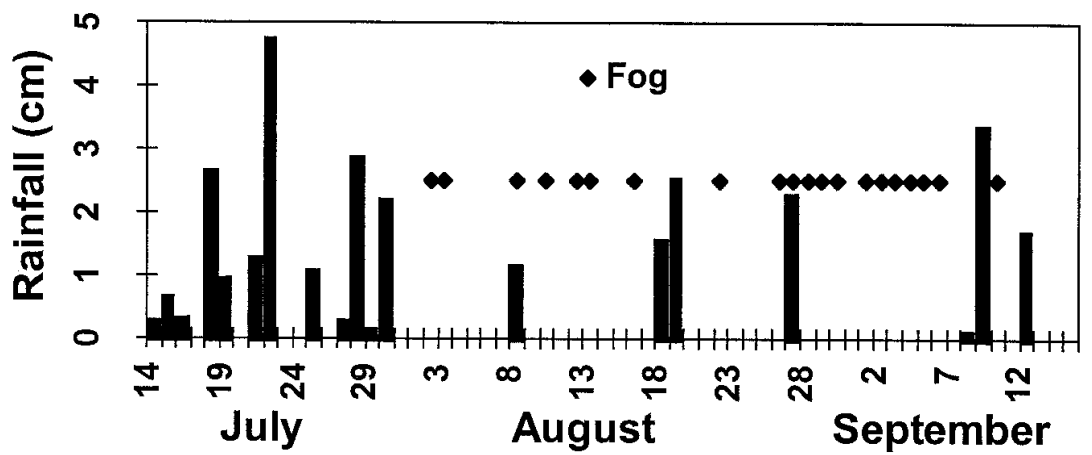

Fig. 1. Days of rainfall accumulation and fog for Watseka, Illinois from 14 July to 15 September 1996. 
has been no further information about SSR in soybean fields in Illinois. The relationship between S. sclerotiorum-infected soybean plants to seed quality characteristics and to yield in maturity group III soybean cultivars has not been reported. The objectives of our study were to determine (i) the relationship of SSR incidence to yield, 100 -seed weight, seed protein and oil content, visual seed quality, and seed germination; and (ii) the percentage of seeds infected and the number of sclerotia found in seed samples from plants infected with S. sclerotiorum.

\section{MATERIALS AND METHODS}

Cultivars and fields. Five maturity group III soybean cultivars, Asgrow A3304 STS (A3304), Pioneer Brand 9342 (P9342), Pioneer Brand 9381 (P9381), Probst (24), and Yale (18), growing in three fields southeast of Watseka, Illinois in 1996, were used in this study. A3304 was planted in field one (18 ha) on 19 May. In field two (29 ha), Probst was planted on 22 May and Yale on 6 June, and in field three (49 ha), P9342 and P9381 were planted on 7 June. Fields one and two were planted by one grower and field three by another. All fields were planted to soybeans in 1994 and corn in 1995. In previous years, SSR symptoms were observed only in field one (farm owners, personal communication).

Plot selection. Within each cultivar, 23 to 26 plots (two rows wide, $76 \mathrm{~cm}$ apart, and $3 \mathrm{~m}$ long) that represented a range of SSR incidences were selected based on surveying the fields for areas that differed in SSR incidence. The plots were selected between 25 September and 9 October when the plants were in the late R7 to R8 growth stages (beginning maturity to full maturity). Within each plot, incidence of SSR was determined by counting the number of plants with SSR stem symptoms divided by the total number of plants in each plot.

Seed harvest and quality measurements. All plots were harvested by hand and threshed by a small plot combine on 12 October. For each plot, data were recorded on yield $(\mathrm{kg})$, 100-seed weight $(\mathrm{g})$, seed moisture $(\%)$, and seed protein and oil content $(\%)$. Seed protein and oil concentrations were determined using infrared reflectance of a $25-\mathrm{g}$ sample of clean seed by the National Center for Agricultural Utilization Research, Peoria, Illinois, and were recorded on a dry weight basis (21). Visual seed quality was rated according to the amount and degree of wrinkled, cracked, greenish, or moldy seeds, using a scale of 1 = very good, $2=$ good, 3 = fair, 4 $=$ poor, and $5=$ very poor $(20,23)$.

Seed germination, sclerotia counts, and seedborne incidence. Seeds from all cultivars were stored at $10^{\circ} \mathrm{C}$ until evaluation. For each cultivar, 400 seeds per plot were placed on moist germination pads and incubated in a seed germinator at $20^{\circ} \mathrm{C}$. After 5 days of incubation, seed germination was recorded. Seeds were considered germinated if the radicals were longer than the length of the seed. Seedborne incidence of $S$. sclerotiorum was determined by di- viding the number of seeds that produced mycelia and sclerotia during the incubation period by the total number of seeds sampled. For each cultivar, except Yale, sclerotia were counted in a 300-g seed sample from each plot.

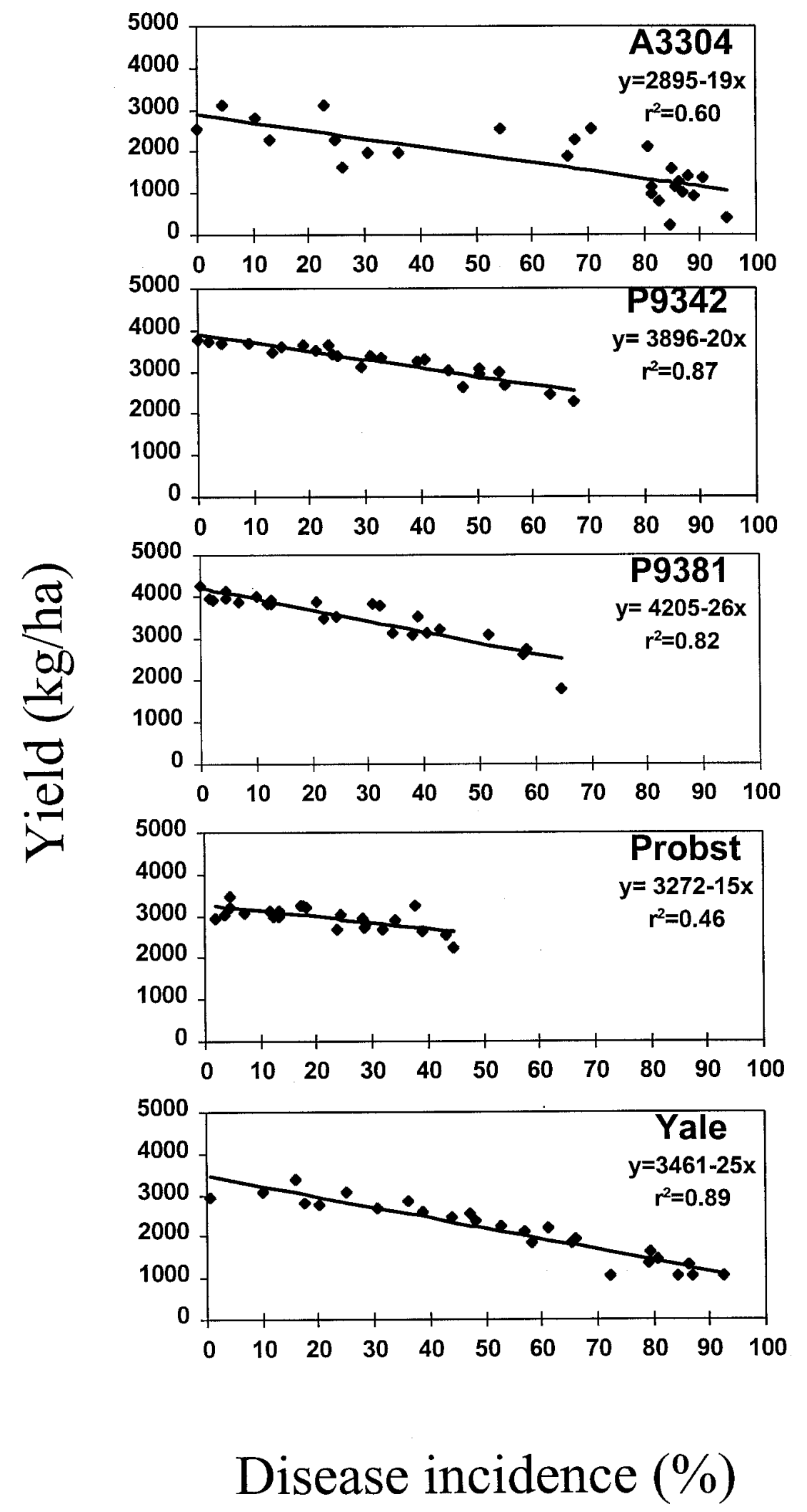

Fig. 2. Regression of Sclerotinia stem rot incidence to yield for soybean cultivars Asgrow A3304 STS, Pioneer Brands 9342 and 9381, Probst, and Yale. 
Statistical analysis. A regression of yield on SSR incidence was conducted for each cultivar. Correlation coefficients of SSR incidence to yield, 100-seed weight, seed protein and oil content, visual seed quality, seed germination, and the number of sclerotia counted in a $300-\mathrm{g}$ samples were determined. Significance was at $P<$ 0.05 unless otherwise stated.

\section{RESULTS AND DISCUSSION}

Data from the Watseka climatological station (Midwestern Climate Center, Champaign, IL), reported that July, August, and September temperatures averaged $21.7,21.8$, and $17.2^{\circ} \mathrm{C}$, and rainfall per month totaled $16.6,7.4$, and $9.1 \mathrm{~cm}$, respectively (Fig. 1). Of 64 days from midJuly to mid-September, 21 days had rainfall accumulation, and 22 days had fog. These weather conditions were favorable for S. sclerotiorum to infect and colonize soybean plants, allowing areas with up to $90 \%$ SSR incidence to occur in two fields. The moist, cool environmental conditions that occurred during our study corroborated other reports that have shown the importance of environmental conditions for disease development $(5,10,13,16)$.

Determination of resistant and susceptible soybean cultivars to $S$. sclerotiorum has been accomplished by determining the SSR incidence ranges under field conditions (4). In our study, Probst had the smallest range of SSR incidence (2 to $45 \%$ ), followed by 0 to $65 \%$ for P9381, 0 to $68 \%$ for P9342, 1 to $93 \%$ for Yale, and 0 to $95 \%$ for A3304. Although Probst and Yale were planted in the same field, the SSR incidence on Probst was considerably lower. It is conceivable that Probst may have more inherent resistance than Yale; however, other factors, such as inoculum density, plant canopy closure, and prior long-term cropping patterns in that field, are not known. Since the cultivars were planted at different times (Probst 16 days prior to Yale), this delay in planting may have influenced disease incidence. Weather conditions during flowering are extremely important for infection. The differences in cultivar maturities or, in this case, planting dates often make field evaluations for resistance to SSR difficult and inconsistent. The window of infection for this disease is rather limited and dependent on timing of ascospore showers, host flowers, and weather conditions.

Regression of yield on SSR incidence for each cultivar was significant (Fig. 2). The yield of Probst was affected less than other cultivars. For every $10 \%$ increase in SSR incidence, yields decreased by 147 , 194, 203, 254, and $263 \mathrm{~kg} / \mathrm{ha}$ for Probst, A3304, P9342, Yale, and P9381, respectively. These results are similar to a previous report from Michigan, where yields were reduced by $235 \mathrm{~kg} / \mathrm{ha}$ for every $10 \%$ increase in SSR incidence (7). Differences in yield among cultivars with SSR may indicate that cultivars differ in their levels of tolerance to SSR. Tolerance has been defined as a measure of the relative yield response of two or more host genotypes to increasing pathogen population density levels (19). For our study, we defined tolerance as the yield response of soybean cultivars at specified levels of SSR incidences. Tolerance, along with resistance, may be an important factor to consider when evaluating the performance of soybean cultivars under field conditions.

Soybean yields consist of components like pods per plant, seeds per pod, and seed weights. In our study, only seed weight was measured, and it was either positively or negatively correlated with SSR incidence depending upon the cultivar. The 100-seed weight of A3304 significantly increased from 12 to $21 \mathrm{~g}$ when SSR incidence increased, whereas the 100-seed weight of P9381 and Yale significantly decreased from 16 to $13 \mathrm{~g}$ and from 16 to $12 \mathrm{~g}$, respectively, as SSR incidence increased (Table 1). Because of these varying results, it is likely that other yield components (e.g., pods per plant and seeds per pod) may have been affected by SSR incidence. In addition, the actual infection site on the plant (e.g., upper verses lower infection site on stems) may have affected seed weights. Further research is needed to determine which yield components are most affected not only by SSR incidence but also by the severity or the degree of fungal colonization.

There were significant correlations between SSR incidence, seed protein and oil content, and visual seed quality (Table 1). Seed protein content of A3304 signifi- cantly increased from 41 to $44 \%$ when SSR incidence increased, but this was not the case for the other four cultivars. Seed oil content was negatively $(P<0.05)$ correlated to SSR incidence for P9381 and Yale. Visual seed quality of each cultivar was significantly reduced when SSR incidence increased. For example, the seed quality of Yale decreased from 1 to 3 as SSR incidence increased from 1 to $93 \%$.

Seed germination ranged from 96 to $100 \%$ for P9381, from 94 to $100 \%$ for Yale, from 93 to $100 \%$ for P9342, from 72 to $99 \%$ for Probst, and from 63 to $99 \%$ for A3304. For each cultivar, except Probst, seed germination significantly decreased when SSR incidence increased (Table 1). Only Probst and A3304 had mean seed germination rates lower than $90 \%$. The number of sclerotia in a $300-\mathrm{g}$ seed sample significantly increased when SSR incidence increased (Table 1). Sclerotial counts in a $300-\mathrm{g}$ seed sample ranged from 0 to 33 for P9342, 0 to 48 for P9381, and 0 to 23 for Probst. The seedborne incidence S. sclerotiorum was $0.3,0.3,0.3,0.4$ and $0.7 \%$ in A3304, P9381, Yale, Probst, and P9342, respectively. This percentage of seedborne infection is somewhat greater than what was reported from eight normalappearing seed lots that had an incidence of seed infection ranging from 0.07 to $0.1 \%$ (15).

By using plots from growers' fields, we found that yield losses for five soybean cultivars varied from 147 to $263 \mathrm{~kg} / \mathrm{ha}$ for every $10 \%$ increase in SSR incidence. The differences in yield losses among cultivars is an important consideration with respect to developing resistance and tolerance to SSR. A number of commercial soybean seed companies now advertise cultivars with tolerance to SSR. Although yields of these commercial cultivars may be good, it is not known if yields were compared as in our study using different levels of SSR incidence. There is a need in the soybean seed industry to compare commercial "tolerant" cultivars in plots where disease incidence and severity levels can be defined in order to compare yield under varying disease levels. Further studies need to determine which components of yields are most affected by SSR. In addition, our study showed that seed quality characteris-

Table 1. Correlation coefficients (r) relating Sclerotinia stem rot incidence to yield, seed protein content, seed oil content, 100-seed weight, visual seed quality, seed germination, and the number of sclerotia in a 300-g seed sample in five cultivars

\begin{tabular}{lccccccc}
\hline Cultivars & Yield (kg/ha) & 100-seed wt. (g) & Protein $(\%)$ & Oil (\%) & Seed quality & Germination $(\%)^{\mathbf{b}}$ & Sclerotia per 300 g $^{\mathbf{2}}$ \\
\hline Asgrow A3304 STS & $-0.77^{*}$ & $0.49^{*}$ & $0.40^{*}$ & -0.19 & $0.84^{*}$ & $-0.52^{*}$ & 0.27 \\
Pioneer Brand 9342 & $-0.93^{*}$ & -0.27 & 0.29 & -0.24 & $0.48^{*}$ & $-0.66^{*}$ & $0.59^{*}$ \\
Pioneer Brand 9381 & $-0.91^{*}$ & $-0.57^{*}$ & 0.05 & $-0.40^{*}$ & $0.77^{*}$ & $-0.62^{*}$ & $0.84^{*}$ \\
Probst & $-0.68^{*}$ & -0.05 & -0.12 & -0.03 & $0.66^{*}$ & -0.23 & $0.68^{*}$ \\
Yale & $-0.94^{*}$ & $-0.43^{*}$ & 0.17 & $-0.45^{*}$ & $0.84^{*}$ & $-0.46^{*}$ & n.d. $^{\text {d }}$ \\
\hline
\end{tabular}

${ }^{a}$ Visual seed quality $(1=$ very good, $2=$ good, $3=$ fair, 4 = poor, $5=$ very poor $)$ rated according to the amount and degree of wrinkled, cracked, greenish, or moldy seeds.

${ }^{\mathrm{b}}$ Germination based on the percentage of seeds with radicals longer than the length of the seed.

c $*$ significant at $P<0.05$.

${ }^{\mathrm{d}}$ Not determined. 
tics were affected when plants were infected with $S$. sclerotiorum. The most obvious effect was the reduction in visual seed quality and seed germination, with some reduction in oil content. Seed infection was relatively low, as was previously reported (15), but seed beans contaminated with sclerotia, infected seeds, or both may be an important source of inoculum, especially to fields that are not already infested with S. sclerotiorum.

\section{ACKNOWLEDGMENTS}

We would like to thank E. O. Johnson and L. S. Kull for their assistance in the field; C. A. Bradley for his assistance in the lab; H. and S. Schroeder and R. and C. Leitz for the use of their crops; and the USDA National Center for Utilization Research Center in Peoria, IL, for evaluating the seed protein and oil content of all plots.

\section{LITERATURE CITED}

1. Abawi, G. S., Provvidenti, R., Crosier, D. C., and Hunter, J. E. 1978. Inheritance of resistance to white mold disease in Phaseolus coccineus. J. Hered. 69:200-202.

2. Anderson, F. N., Steadman, J. R., Coyne, D. P., and Schwartz, H. F. 1974. Tolerance to white mold in Phaseolus vulgaris dry edible bean types. Plant Dis. Rep. 58:782-784.

3. Boland, G. J., and Hall, R. 1986. Growthroom evaluation of soybean cultivars for resistance to Sclerotinia sclerotiorum. Can. J. Plant Sci. 66:559-564.

4. Boland, G. J., and Hall, R. 1987. Evaluating soybean cultivars for resistance to Sclerotinia sclerotiorum under field conditions. Plant Dis. 71:934-936.
5. Boland, G. J., and Hall, R. 1988. Epidemiology of Sclerotinia stem rot of soybean in Ontario. Phytopathology. 78:1241-1245.

6. Chamberlain, D. W. 1951. Sclerotinia stem rot of soybeans. Plant Dis. Rep. 35:490-491.

7. Chun, D., Kao, L. B., and Lockwood, J. L. 1987. Laboratory and field assessment of resistance in soybean to stem rot caused by Sclerotinia sclerotiorum. Plant Dis. 71:811-815.

8. Cline, M. N., and Jacobsen, B. J. 1983. Methods for evaluating soybean cultivars for resistance to Sclerotinia sclerotiorum. Plant Dis. 67:784-786.

9. Coyne, D. P., Steadman, J. R., and Schwartz, H. F. 1977. Reaction of Phaseolus dry bean germplasm to Sclerotinia sclerotiorum. Plant Dis. Rep. 61:226-230.

10. Grau, C. R. 1988. Sclerotinia stem rot of soybean. Pages 56-149 in: Soybean Diseases of the North Central Region. T. D. Wyllie and D. H. Scott, eds. APS Press, St. Paul, MN.

11. Grau, C. R., Adee, E. A., and Oplinger, E. S. 1994. An integrated approach to control Sclerotinia stem rot (White Mold) in soybean. Pages 183-196 in: Proc. Integrated Crop Management Conf., Ames, IA.

12. Grau, C. R., and Bissonnette, H. L. 1974. Whetzelinia stem rot of soybean in Minnesota. Plant Dis. Rep. 59:693-695.

13. Grau, C. R., and Radke, V. L. 1984. Effects of cultivars and cultural practices on Sclerotinia stem rot of soybean. Plant Dis. 68:56-58.

14. Grau, C. R., Radke, V. L., and Gillespie, F. L. 1982. Resistance of soybean cultivars to Sclerotinia sclerotiorum. Plant Dis. 66:506-508.

15. Hartman, G. L., Kull, L., and Huang, Y. H. 1998. Occurrence of Sclerotinia sclerotiorum in soybean fields in east-central Illinois and enumeration of inocula in soybean seed lots. Plant Dis. 82:560-564.
16. Nelson, B. D. Helms, T C , and Kural, 1991. Effects of temperature and pathogen isolate on laboratory screening of soybean for resistance to Sclerotinia sclerotiorum. Can. J. Plant Sci. 71:347-352.

17. Nelson, B. D, Helms, T. C, and Olson, M. A. 1991. Comparison of laboratory and field evaluations of resistance in soybean to Sclerotinia sclerotiorum. Plant Dis. 75:662-665.

18. Nickell, C. D., Noel, G. R., Tharp, J. E., Cary, T. R., and Thomas, D. J. 1995. Registration of Yale soybean. Crop Sci. 35:1221-1222.

19. Nutter, R. W. Jr., Teng, P. S., and Royer, M. H. 1993. Terms and concepts for yield, crop loss, and disease thresholds. Plant Dis. 77:211-215.

20. Pracht, J. E., Nickell, C. D., Harper, J. E., and Bullock, D. G. 1994. Agronomic evaluation of non-nodulating and hypernodulating mutants of soybean. Crop Sci. 34:738-740.

21. Rinne, R. W., Gibbons, S., Bradley, J., Seif, R., and Brim, C. A. 1975. Soybean protein and oil percentages determined by infrared analysis. USDA-ARS North Bull. 26, Peoria, IL.

22. Sutton, D. C., and Deverall, B. J. 1983. Studies on infection of bean (Phaseolus vulgaris) and soybean (Glycine max) by ascospores of Sclerotinia sclerotiorum. Plant Pathol. 32:251-261.

23. Wilcox, J. R. 1996. The uniform soybean tests-northern states: 1996. USDA-ARS, West Lafayette, IN

24. Wilcox, J. R., and Abney, T. S. 1995. Registration of Probst soybean. Crop Sci. 35:1713.

25. Wrather, J. A., Anderson, T. R., Arsyad, D. M., Gai, J., Ploper, L. D., Porta-Puglia, A., Ram, H. H., and Yorinori, J. T. 1997. Soybean disease loss estimates for the top 10 soybean producing countries in 1994. Plant Dis. 81:107-110. 